\title{
Development of an algorithm for optimizing the synthesis of leukocyte polypeptides
}

\author{
(C) Larisa V. Volkova, ${ }^{1 *}$ Tatiana A. Grishina, ${ }^{1+}$ and Ekaterina V. Orlova ${ }^{2}$ \\ ${ }^{1}$ Department of Chemistry and Biotechnology. Perm National Research Polytechnic University. \\ Komsomolsky Prospect, 29. Perm, 614990. Perm region. Russia. \\ Phone: +7 (342) 239-15-11. E-mail: tatyana_grishina_1990@mail.ru \\ ${ }^{2}$ Department of Industrial Technology of Medicines with a course of biotechnology. Perm State \\ Pharmaceutical Academy. Polevaya St., 2. Perm, 614990. Perm region. Russia. \\ Phone: +7 (342) 282-58-42. E-mail: tatyana_grishina_1990@mail.ru
}

*Supervising author; ${ }^{+}$Corresponding author

Keywords: polypeptides, leukocytes, hemakontainers, cytapheresis, lyophilization, cryoprotectants.

\begin{abstract}
The article presents experimental data on the influence of various factors on the synthesis of leukocyte polypeptides. It was shown that the productive ability of leukocytes depends on the method of sampling the donor raw materials and the used blood containers. The obtained experimental data indicate a favorable effect of cytapheresis during harvesting of raw materials on polypeptides produced by leukocytes. Assessment of the level of specific activity of polypeptides obtained from raw materials by the method of cytapheresis indicates an increase of 2.4 times. It was also found that the use of the cytapheresis method made it possible to obtain a leukoerythromass with a leukocyte concentration 4 times higher than using the classical method of taking raw materials. The results of the influence of the culture regime of leukocyte cells on the level of specific activity of the synthesized polypeptides are presented. It was shown that the suspension mode of cultivation, in which the level of specific activity of polypeptides increases 1.3 times, is optimal for the synthesis of leukocyte polypeptides. The conditions for the synthesis of polypeptides by leukocytes were optimized. It was established by calculation that the leukocyte concentration of 8 billion/l and the mixing rate of the culture medium of $32 \mathrm{rpm}$ were optimal at the stage of biosynthesis. The effect of L-dextrose and maltose on the residual moisture content of polypeptides in cryoprotectant concentrations from 2.5 to $10 \%$ was studied. In a series of experiments, it was found that maltose at a concentration of $2.5 \%$ is the optimal cryoprotectant for lyophilization of leukocyte polypeptides. According to the results of the experiments, an algorithm for optimizing the synthesis of leukocyte polypeptides was developed, which consists in using the cytapheresis method in the preparation of raw materials and "Terumo" hemakontainers, observing the optimal parameters during the cultivation of leukocytes, and lyophilization of the finished product using a cryoprotectant of maltose at a concentration of $2.5 \%$.
\end{abstract}

\section{References}

[1] E.B. Zhiburt, A.A. Vergopulo. The concept of the order of the Ministry of Health and Social Development of Russia «On the development of clinical transfusiology». Health Manager. 2008. No.9. P.28-31. (russian)

[2] L.V. Volkova, T.A. Grishina, A.G. Volkov. Low molecular weight leukocyte peptides induced by different antigens. Chemical technology and biotechnology. Bulletin of PNRPU. 2015. No.4. P.35-48. (russian)

[3] General monographs.1.7.2.0002.15 Biological methods for testing interferon preparations using cell cultures.

[4] L.V. Volkova, T.A. Grishina. Effect a haemo container different manufacturers on the productive capacity of mammalian cells. Biopharmaceutical Journal. 2019. Vol.11. No.2. P.8-11. (russian)

[5] A.P. Parachonsky. Functional properties of natural peptides and their fragments. Modern high technology. 2007. No.6. P.71-72; URL: http://top-technologies.ru/ru/article/view?id=25017 (accessed: 13.05.2019). (russian)

[6] M.S. Bulkin. Freeze-drying of biological raw materials taking into account fluctuations in industrial technologies. PhD thesis in technical sciences. Moscow. 2010. 17p. (russian) 